\title{
THE FLUORESCENCE AND ABSORPTION OF CERTAIN PLEOCHROIC CRYSTALS OF THE URANYL SALTS.
}

By Edward L. Nichols and H. L. Howes.

$\mathrm{W}^{\mathrm{B}}$

ELL-FORMED crystals of certain of the uranyl salts show a marked pleochroism. When viewed through a Nicol prism their color changes from a yellowish-green to a very pale yellowish white when the plane of the Nicol is turned through $90^{\circ}$.

It has been shown in a recent paper ${ }^{1}$ that in the case of the double chlorides of uranyl (i. e., $\mathrm{UO}_{2} \mathrm{Cl}_{2} \cdot 2 \mathrm{NH}_{4} \mathrm{Cl}+2 \mathrm{H}_{2} \mathrm{O} ; \mathrm{UO}_{2} \mathrm{Cl}_{2} 2 \mathrm{KCl}+$ $2 \mathrm{H}_{2} \mathrm{O} ; \mathrm{UO}_{2} \mathrm{Cl}_{2} 2 \mathrm{RbCl}+2 \mathrm{H}_{2} \mathrm{O}$ and $\mathrm{UO}_{2} \mathrm{Cl}_{2} 2 \mathrm{CsCl}$ ) these changes of color are connected with striking and significant variations in the fluorescence and absorption spectra.

All four of these double chlorides, like the ammonium uranyl chloride, the fluorescence and absorption spectra of which have lately been described by Nichols and Merritt in the Physical Review, ${ }^{2}$ differ from the other uranyl salts thus far studied in the greater degree of resolution exhibited by their spectra at $+20^{\circ}$.

Their spectra are all of the same type, consisting of equidistant groups of bands, the homologous members of which form series with constant frequency intervals. Each series terminates towards the violet in the so-called reversing region where, as will be seen from Fig. I, its last

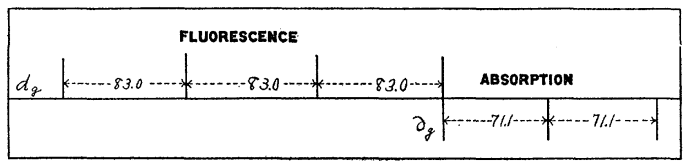

Fig. 1.

member is identical in position with the first member of a series of absorption bands extending into the ultra-violet and having likewise a constant but shorter interval. The further resolution effected by cooling the crystal to the temperature of liquid air is in general of the same character as that observed in the case of the ammonium uranyl chloride:

1 Nichols and Howes, Proceedings of the National Academy of Sciences, Vol. I., p. 444, Aug., I9I5.

${ }^{2}$ Nichols and Merritt, Phys. Rev., Series II., Vol. 6, Nov., I9r5. 
$i$. e., the bands are usually resolved into doublets, the components of which, in some cases, particularly noticeable in the absorption spectrum, show indications of further complexity.

It has further been shown ${ }^{1}$ that these doublets are polarized, the planes of vibration of the components being at right angles to one another, so that by viewing the spectrum through a Nicol prism a resolution of the bands of fluorescence and absorption is obtained.

The relation of these two effects has already been discussed in the case of the ammonium uranyl chloride; and it is the purpose of the present paper to study in greater detail, for the purposes of comparison, the polarized fluorescence and absorption of these four double chlorides at $20^{\circ}$ and $-185^{\circ}$.

The polarization of the fluorescent light from crystals, first noted by Grailich in $1857^{2}$ has since been studied by Maskalyne, ${ }^{3}$ von Lommel, ${ }^{4}$ E. Wiedemann, ${ }^{5}$ Sohncke, ${ }^{6}$ Schmidt,${ }^{7}$ H. Becquerel ${ }^{8}$ and Pochettino. ${ }^{9}$

With the exception of the work of Becquerel, in which low temperatures were employed, the authors cited above have dealt chiefly with fluorescence of the usual type, consisting of broad bands. In such cases the most that can be done is to determine the direction of vibration and estimate the proportion of polarized light.

In the measurements to be described in the present paper the apparatus depicted in Fig. 2 was used.

Within the collimator of a spectroscope of constant deviation a rhomb of calcite $R$ was so mounted as to give two vertically displaced images of the slit, and these by suitable adjustment of the length of the slit could be rendered contiguous without overlapping.

The crystal $C$ was mounted before the slit and turned about the axis of the collimator until the planes of vibration of the transmitted light coincided with planes of transmission of the rhomb.

For the study of fluorescence the light from a carbon arc $A$ after passage through the condensing lens $L$, the water cell $W$ and a light filter $F$, was employed for excitation. The filter was opaque to light of a wave-length greater than $.45 \mu$, so that the fluorescence appeared on a black background. When absorption spectrographs were required a

${ }^{1}$ Nichols and Howes, loc. cit.

${ }^{2}$ Grailich, Krystall-optische Untersuchungen, Wien, I858.

${ }^{3}$ Maskalyne, Proc. Royal Society, XXVIII., p. 479.

${ }^{4}$ von Lommel, Wiedemann's Annalen, VIII., p. 634.

5 E. Wiedemann, Wiedemann's Annalen, IX., p. 158.

${ }^{6}$ Sohncke, Wiedemann's Annalen, LVIII., p. 4I 7.

${ }^{7}$ G. C. Schmidt, Wiedemann's Annalen, LX., p. 740.

${ }^{8} \mathrm{H}$. Becquerel, Comptes Rendus, CXLIV., p. $67 \mathrm{r}$.

9 Pochettino, Nuovo Cimento (V.), I8, 1909. 
pale blue screen was substituted, and the carbon arc was replaced by a I,ooo-watt nitrogen-filled tungsten lamp.

Many crystals were produced before any were found which gave complete separation of the two polarized components. A mere inspection of the crystals was not a sufficient criterion; but when transmitted light polarized parallel to one of the planes of vibration of the crystal was used, the presence of only one of the two absorption spectra was

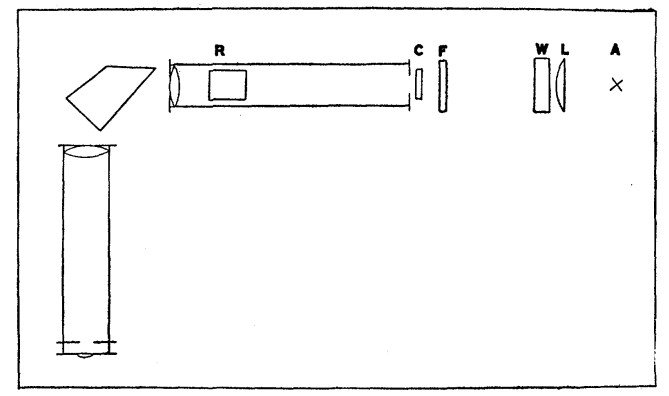

Fig. 2.

found to afford a very delicate test, both for the adjustment of the apparatus and the homogeneity of the crystal. In accordance with the usage adopted in the paper already cited ${ }^{1}$ we shall call that component of the spectrum due to vibrations in the more transparent direction of the crystal, the white component, while the component at right angles to this will be designated as the green component. The stronger fluorescence, as might be expected, corresponds to the green polarization.

The four double chlorides of uranyl which were studied crystallize in triclinic plates. The crystals were so mounted that the flat faces were at right angles to the transmitted light.

The flat faces of the potassium, ammonium and rubidium uranyl chloride crystals correspond to the $(c)$ crystallographic face, while the flat face of caesium chloride crystals corresponds to the $(b)$ crystallographic face. The caesium chloride crystallizes in gypsum-like plates, which were mounted with the longest, $(c)$ crystallographic axis vertical. Since the plane of polarization of the white light is also vertical within a degree or two, light vibrating horizontally is, in this arrangement, less absorbed than light vibrating vertically. As to the direction of vibration of the white light within the crystal, it can be said to be more nearly parallel to the $(a)$ crystallographic axis than to the $(b)$ axis. Rubidium chloride crystallizes in long hexagonal plates. As mounted, plane polarized light was transmitted most freely when the direction of vibra-

${ }^{1}$ Proceedings of the National Academy, I., p. 444. 
VoL. VIII.] FLUORESCENCE OF CRYSTALS OF URANYL SALTS.
No. 4.

tion was parallel to the (a) crystallographic axis. Potassium and ammonium chlorides crystallize in thin plates which approximate more nearly the hexagon in form. Examination of the transmitted light with the aid of a Nicol shows that the same relations exist between the directions of vibration and the crystallographic axes as for the rubidium chloride. ${ }^{1}$

Two polarized fluorescence spectra are always present, provided the crystal is mounted as previously described. It is a remarkable fact that these spectra remain unchanged whether the exciting light is unpolarized or is polarized in a white or green direction, or any other direction. Their character moreover appears to be independent of the direction from which the exciting light enters the crystal. This is in agreement with a general principle established by the study of fluorescence spectra, ${ }^{2}$ that the character and location of a fluorescence band is independent of the nature of the excitation. Changes in the polarized spectra occur, however, as might be expected, if different crystallographic faces are placed at right angles to the axis of the collimator.

Although visual observations were made, the spectra were mapped for the most part from the photographic plates. Two measuring instruments were used - the comparator, and a special combination of lantern and micrometer stage. For locating and measuring the dim bands the latter arrangement was far superior. Occasionally the fluorescence and a portion of the absorption spectrum could be photographed simultaneously to advantage, but more often different screening and various times of exposure were necessary in order to bring out different regions of the absorption. The exposures varied in time from 30 seconds to one hour. The micrometer screw was calibrated in wave-lengths, but reciprocals of the wave-lengths are employed in the plots of the spectra, and the bands are designated in the diagrams and tables by their frequency numbers; i. e., $\mathrm{I} / \mu \times \mathrm{IO}^{3}$, where $\mu$ is the unit of wave-length. The bands of smallest frequency number; $i$. e., of longest wave-length, will be consistently found on the left side of each plot, so that a shift to the violet is indicated by a shift to the right.

\section{A Study of Typical Groups of Bands from the Fluorescence and Absorption Spectra at $+20^{\circ} \mathrm{C}$. \\ In the study of the spectrum of the uranyl ammonium chloride it has recently been shown ${ }^{3}$ that each group of bands consists of five members, \\ 1 The excellent specimens which were finally utilized in this investigation we owe to the persistent and skillful efforts of Mr. D. F. Wilber. \\ 2 Nichols and Merritt, Phys. Rev., Series I., 27, p. 373, rgo8. \\ ${ }^{3}$ Nichols and Merritt, Phys. Rev., Series II., Vol. 6, r9r 5.}


and that each of these bands is double. Since polarization effects a resolution or separation we should expect in general to find five components in each polarized fluorescence group. In the same paper ${ }^{1}$ the bands of one fluorescence group have been designated as $b, c, d, e$ and $a$, and the same nomenclature will be employed here.

A typical fluorescence group for each of the four salts is indicated in Fig. 3. The bands above the horizontal line are the

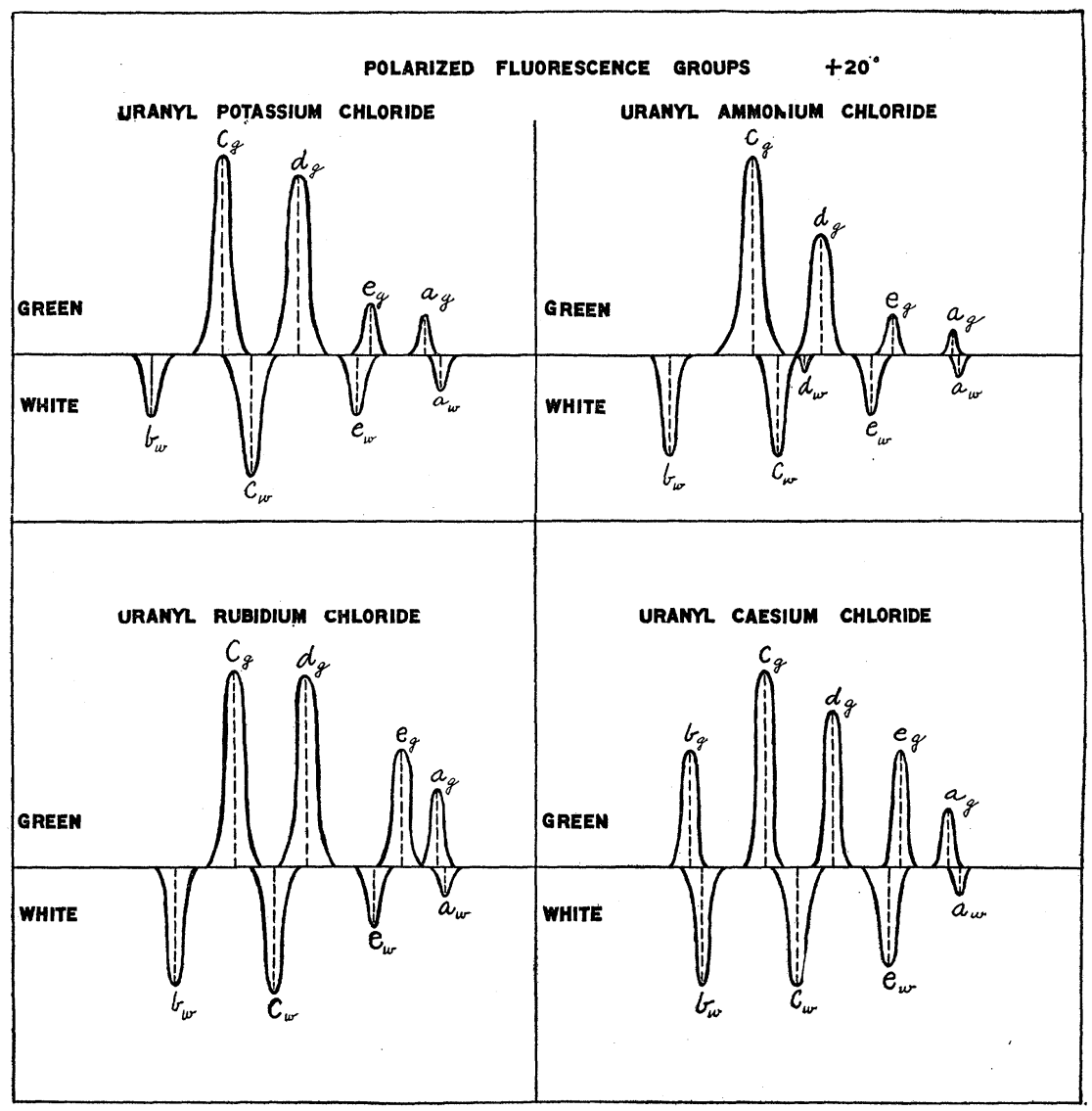

Fig. 3.

green polarization components $\left(b_{g}, c_{g}\right.$, etc.), those below, the white polarization components $\left(b_{w}, c_{w}\right.$, etc.). The lengths of the bands give an approximate idea of their intensities, although the difference in intensity between a strong $c$ band and a weak $a$ band cannot be shown to advantage in such a diagram. The positions of the

${ }^{1}$ Nichols and Merritt, loc. cit. 
crests of the bands are taken from the observed values, to be found in Table I, but the width and form of the bands are more or less arbitrary, being the expression of a judgment based on a large number of observations.

From this figure it will be seen that bands $c, e$ and $a$ of uranyl potassium chloride appear as doublets, polarized at right angles. Band $b$ has no green component visible but, as will be shown in a subsequent paragraph, at $-185^{\circ}$ a green component is present, which lies nearer the red than $b_{w}$. Bands $c_{g}$ and $c_{w}$ are the two components of band $c$, while no component of band $d$ has been found on the white side. Bands $e$ and $a$ are also well resolved, the white component of band $e$ is of longer wave-length than the green component, while the white components of $c$ and $a$, and probably of $b$, are of shorter wave-length than their respective green components.

The uranyl ammonium chloride group shows a strong similarity to the preceding group. All except band $b$ appear as polarized doublets. Components $d_{w}$ and $a_{w}$ were discerned only with the greatest difficulty.

The uranyl rubidium chloride group is very similar to the uranyl potassium chloride group. Band $b_{g}$ is missing, but as in the potassium chloride there is a $-\mathrm{I} 85^{\circ}$ component to the red of $b_{w}$. Component $c_{w}$ has a position nearer $d_{g}$ than has $c_{w}$ in the preceding spectra. This is also the condition existing in the caesium chloride spectrum, and it is possible,-since no $d_{w}$ component is visible in either spectrum, that $d_{w}$ is very $\operatorname{dim}$, and hidden in $c_{w}$.

Uranyl caesium chloride gives the most satisfactory set of fluorescence bands, since both components of band $b$ are present, and the $c, e$ and $a$ components are very well separated. It is interesting to note that $b_{g}$ is of longer wave-length than $b_{w}$, as is the $-185^{\circ}$ component of $b_{g}$ in the preceding salts.

It has been previously stated that the absorption spectra, like the fluorescence spectra, are composed of series, which begin with the bands which terminate the fluorescence series. The absorption bands which lie nearest the fluorescence region can also be arranged in recurring groups. The absorption series will be designated $\beta, \gamma, \partial, \epsilon$ and $\alpha$; since they join the $b, c, d, c$ and $a$ fluorescence series, respectively. The $\epsilon$ and $\alpha$ series are the strongest in the reversing region, but gradually vanish while the $\partial$ series becomes stronger towards the ultra-violet. Fig. 4 gives a typical absorption group for each of the four salts. As before, the components above the line belong to the green; those below to the white polarization.

By comparing the uranyl potassium chloride absorption group in 
Fig. 4 with the fluorescence group of the same salt in Fig. 3 it will be seen that there is no $\beta_{g}$ component present, as there was no $b_{g}$ component present, but that $\gamma_{g}, \partial_{g}, \epsilon_{g}$, and $\alpha_{g}$, corresponding to series $c_{g}, d_{g}, e_{g}$ and $a_{g}$ are present and that there are no other series represented. Although the relative intensities of the absorption components are almost reversed when compared with the relative intensities of the fluorescence bands, the same spacing exists between the green components of both

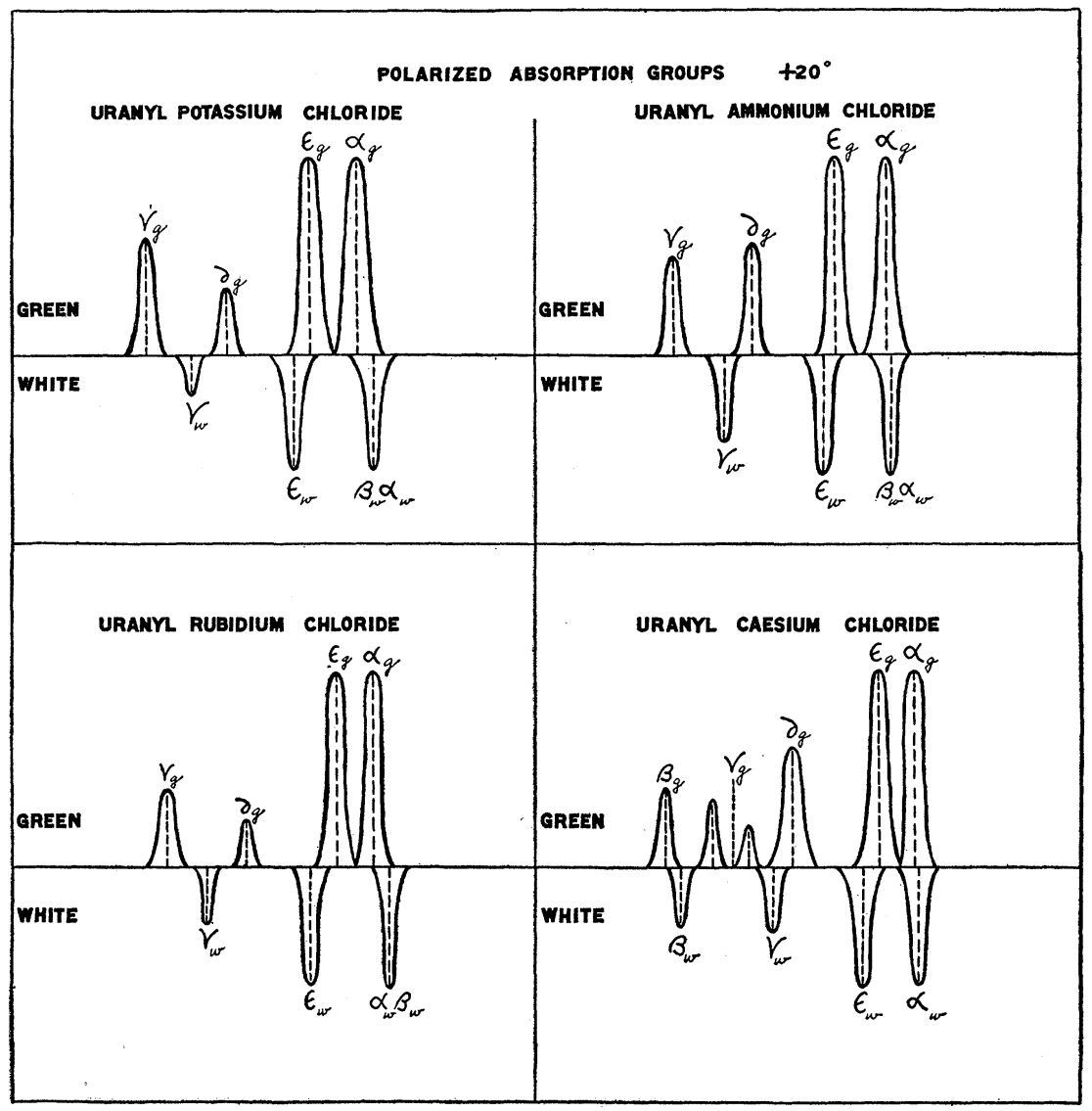

Fig. 4.

fluorescence and absorption. In the white polarization group, $\gamma_{w}$ corresponds, in position, to $c_{w}$, and $\epsilon_{w}$ to $e_{w}$, while $\beta_{w} a_{w}$ serves both $b_{w}$ and $a_{w}$ series in the following way: $b_{w}$ is the first member of each fluorescence group, while $a_{w}$ is the band of the preceding group which is nearest to $b_{w}$. As the fluorescence intervals of both the $a$ and $b$ series are approximately 83 frequency units, and $a_{w}$ is $\mathrm{I} 2$ units distant from $b_{w}$, the reversing 
band of the $a_{w}$ series must coincide with the second member of the $\beta_{w}$ absorption series, since it is $7 \mathrm{I}$ units from the reversing band $b_{w}$ or $\beta_{w}$. The $\partial_{w}$ component is absent, as is $d_{w}$, and there are no superfluous series.

The absorption group of the uranyl ammonium chloride is very similar to that of the potassium chloride. Again the $\beta_{g}$ component, like the $b_{g}$ component, is absent, but the other fluorescence series are represented by absorption series, save that no component of $\partial$ was found to join the very weak $d_{w}$ fluorescence band.

Uranyl rubidium chloride shows a grouping analogous to that of the potassium and ammonium chloride, while the uranyl caesium chloride group is only slightly different.

A $\beta_{g}$ series is present, which is properly related to the $b_{g}$ series, so that $\beta_{g}$ and $\beta_{w}$ are in the same relative positions as are $b_{g}$ and $b_{w}$.

No green polarized component joins the $c_{g}$ component. The dotted line shows where an absorption component would have to be placed to have the proper relation, according to our theory. The $\gamma_{g}$ band is evidently complex. $\gamma_{w}$ is present, however, as a single band, and the $\partial, \epsilon$ and $\alpha$ components occupy positions which agree with their corresponding fluorescence components. $\beta_{w}$ and $\alpha_{w}$ are here separate.

\section{A Detalled Study of the Relation between Fluorescence and Absorption Series.}

In Fig. 5 are indicated two complete fluorescence groups and two complete absorption groups for each of the eight spectra. The remarkable fact is that although no observed fluorescence bands have been omitted which fall within the frequency numbers plotted, each fluorescence series has its properly related absorption series, and with the exception of the complex $\gamma_{g}$ series of the caesium chloride not a superfluous absorption series is present. Fluorescence bands are designated by the solid lines above the horizontal, and absorption bands by the solid lines below the horizontal. The dotted lines above the absorption bands represent the hypothetical positions of absorption bands, computed in the following manner.

The average interval for the series in question was computed from all available observations on the bands which belong to it, carefully weighted. A hypothetical position for the band in the reversing group was then found by adding this interval to the average of the observations on the position of the preceding band of the series. This hypothetical position was taken as the starting point of the corresponding absorption series, the hypothetical positions of the subsequent members being found by addition of the weighted average for the observed interval of that series. 
By reference to Fig. 5 and to Tables I. and III. the reader can note the general agreement between observed and calculated positions; also the occasional discrepancies. In the spectra of uranyl ammonium chloride and uranyl rubidium chloride, for example, the $b_{w}$ and $a_{w}$ series are spaced at such an interval that $\alpha_{w}$ and $\beta_{w}$ cannot coincide, as will be

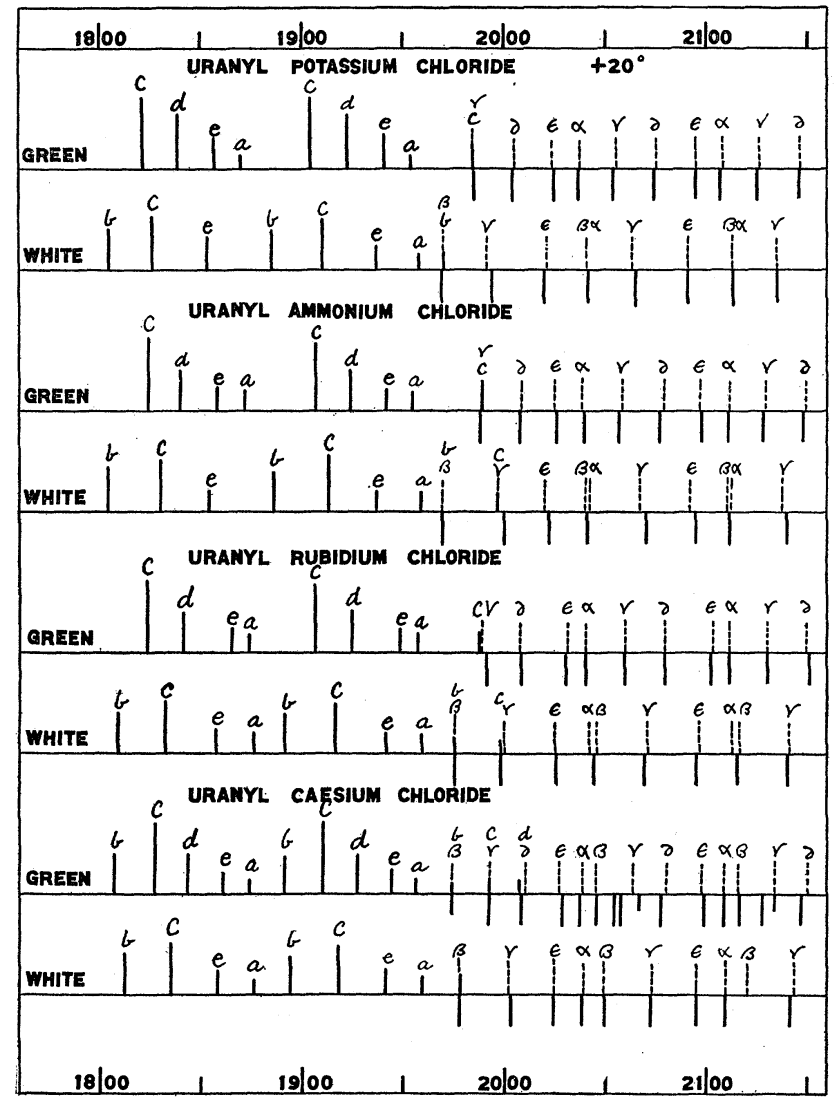

Fig. 5.

seen from Fig. 5. The observed $\beta_{w} \alpha_{w}$ bands occupy positions between the assumed positions of the $\beta$ and $\alpha$ series, which tends to show that the $\beta \alpha$ band is a narrow doublet. The fact that a few of the observed absorption bands do not appear to be in their proper places can be readily explained when it is remembered that there is sufficient experimental evidence to lead to the belief that many of the absorption bands are doublets, consisting of a strong and a weak component. The breaks in a few of the absorption series, as in the $\epsilon_{g}$ and $\alpha_{g}$ series of the uranyl ammonium chloride, are undoubtedly due to the sudden increase in 
VoL. VIII.] FLUORESCENCE OF CRYSTALS OF URANYL SALTS.
No. 4.

TABle I.

Polarized Series at $+20^{\circ}$.

Uranyl Potassium Chloride.

Fluorescence.

\begin{tabular}{|c|c|c|c|c|c|c|c|}
\hline \multicolumn{4}{|c|}{ Green Component. } & \multicolumn{4}{|c|}{ White Component. } \\
\hline$c$ & $d$ & $e$ & $a$ & $b$ & $c$ & $e$ & $a$ \\
\hline$\ldots$ & 1756.3 & 1774.6 & 1788.9 & & $\ldots \ldots$ & 1770.9 & \\
\hline 1821.0 & 1838.6 & 1856.9 & 1871.2 & 1804.2 & 1827.2 & 1853.5 & $\ldots \ldots$ \\
\hline 1903.1 & 1922.0 & 1940.6 & 1955.2 & 1887.1 & 1909.6 & 1937.5 & 1958.0 \\
\hline 1984.6 & $\ldots \ldots$ & $\ldots \ldots$ & $\ldots \ldots \ldots$ & 1970.1 & 1992.0 & $\ldots \ldots \ldots$ & $\ldots \ldots \ldots$ \\
\hline \multicolumn{8}{|c|}{ Absorption. } \\
\hline \multicolumn{4}{|c|}{ Green Component. } & \multicolumn{4}{|c|}{ White Component. } \\
\hline$\gamma$ & $\delta$ & $\epsilon$ & $\alpha$ & $\beta a$ & $\gamma$ & $\epsilon$ & \\
\hline 1985.7 & 2004.4 & 2024.7 & 2036.7 & 1968.1 & 1994.4 & 2019.8 & \\
\hline 2054.2 & 2073.8 & 2094.7 & 2106.7 & 2039.6 & 2064.8 & 2090.7 & \\
\hline 2125.4 & 2145.5 & 2165.9 & $\ldots \ldots$ & 2111.0 & 2134.9 & 2160.8 & \\
\hline$\ldots \ldots \ldots$ & $\ldots \ldots \ldots$ & $\ldots \ldots \ldots$ & $\ldots \ldots \ldots$ & 2179.1 & $\ldots \ldots \ldots$ & $\ldots \ldots \ldots$ & \\
\hline$\ldots \ldots$ & 2287.8 & $\ldots \ldots \ldots$ & 2247.7 & $\ldots \ldots \ldots$ & $\ldots \ldots$ & $\ldots \ldots \ldots$ & \\
\hline$\ldots \ldots$ & 2359.0 & $\ldots \ldots \ldots$ & $\ldots \ldots \ldots$ & 2398.1 & $\ldots \ldots \ldots$ & $\ldots \ldots \ldots$ & \\
\hline$\ldots$ & $\ldots \ldots \ldots$ & $\ldots \ldots \ldots$ & 2602.4 & $\ldots \ldots \ldots$ & $\ldots \ldots \ldots$ & $\ldots \ldots \ldots$ & \\
\hline 2624.0 & $\ldots \ldots$ & $\ldots \ldots \ldots$ & 2673.8 & $\ldots \ldots \ldots$ & 2635.0 & $\ldots \ldots$ & \\
\hline 2695.4 & $\ldots \ldots$ & $\ldots \ldots \ldots$ & 2743.5 & $\cdots$ & $\ldots \ldots \ldots$ & $\ldots \ldots \ldots$ & \\
\hline
\end{tabular}

Uranyl Ammonium Chloride.

Fluorescence.

\begin{tabular}{c|c|c|c||c|c|c|c}
\hline \multicolumn{6}{c||}{ Green Component. } & \multicolumn{4}{c}{ White Component. } \\
\hline$c$ & $d$ & $e$ & $a$ & $b$ & $c$ & $e$ & $a$ \\
\hline 1742.1 & 1756.4 & 1775.8 & 1790.0 & $\ldots \ldots \ldots$ & 1748.4 & 1770.9 & $\ldots \ldots$ \\
1824.0 & 1840.3 & 1857.6 & 1874.1 & 1804.2 & 1829.6 & 1853.8 & $\ldots \ldots$ \\
1907.0 & 1923.6 & 1941.6 & 1957.8 & 1886.8 & 1912.9 & 1937.0 & 1959.0 \\
1990.0 & $\ldots \ldots \ldots$ & $\ldots \ldots \ldots \ldots$ & $\ldots \ldots \ldots$ & 1970.6 & $\ldots \ldots \ldots$ & $\ldots \ldots \ldots$ \\
\hline
\end{tabular}

Absorption.

\begin{tabular}{|c|c|c|c|c|c|c|}
\hline \multicolumn{4}{|c|}{ Green Component. } & \multicolumn{3}{|c|}{ White Component. } \\
\hline$\gamma$ & $\delta$ & $\epsilon$ & $a$ & $\beta a$ & $\gamma$ & $\epsilon$ \\
\hline 1988.5 & 2007.9 & 2026.5 & 2039.9 & 1970.5 & 1999.8 & 2022.4 \\
\hline 2057.3 & 2077.3 & 2098.1 & 2110.9 & 2042.6 & 2070.2 & 2094.7 \\
\hline 2128.1 & 2146.9 & 2169.8 & 2182.3 & 2114.1 & 2140.5 & 2166.0 \\
\hline$\ldots \ldots \ldots$ & 2218.1 & 2240.1 & 2256.8 & 2185.0 & $\ldots \ldots \ldots$ & $\ldots \ldots$ \\
\hline & 2289.7 & 2313.2 & 2327.7 & $10^{\circ}$ & & 2311.8 \\
\hline & 2360.8 & 2383.3 & 2399.2 & & & 2381.8 \\
\hline$\ldots \ldots \ldots$ & 2431.4 & 2455.8 & $\ldots \ldots \ldots$ & & & \\
\hline$\ldots \ldots \ldots$ & 2500.8 & 2525.9 & $\ldots \ldots$ & & & \\
\hline$\ldots \ldots \ldots$ & 2571.4 & $\ldots \ldots \ldots$ & $\ldots \ldots$ & & & \\
\hline 2623.3 & $\ldots \ldots$ & $\ldots \ldots \ldots$ & $\ldots \ldots \ldots$ & & & \\
\hline
\end{tabular}


Uranyl Rubidium Chloride.

Fluorescence.

\begin{tabular}{|c|c|c|c|c|c|c|c|}
\hline \multicolumn{4}{|c|}{ Green Component. } & \multicolumn{4}{|c|}{ White Component. } \\
\hline$c$ & $d$ & $e$ & $a$ & $b$ & $c$ & $e$ & $a$ \\
\hline 1739.1 & 1757.6 & 1781.9 & $\cdots$ & $\cdots$ & 1750.6 & 1774.7 & 1793.6 \\
\hline 1822.7 & 1840.9 & 1865.3 & 1873.7 & 1808.8 & 1832.4 & 1858.0 & 1875.5 \\
\hline 1905.0 & 1923.9 & 1948.8 & 1956.9 & 1891.1 & 1916.4 & 1941.6 & 1959.5 \\
\hline 1986.9 & 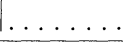 & $\ldots \ldots$ & $\ldots$ & 1975.3 & $\cdots$ & $\therefore \ldots$ & $\cdots$ \\
\hline \multicolumn{8}{|c|}{ Absorption. } \\
\hline \multicolumn{4}{|c|}{ Green Component. } & \multicolumn{4}{|c|}{ White Component. } \\
\hline$\gamma$ & $\delta$ & $\epsilon$ & $\alpha$ & $\alpha \beta$ & $\gamma$ & $\epsilon$ & \\
\hline 1991.2 & 2008.4 & 2030.0 & 2040.4 & 1973.7 & 1999.2 & 2024.3 & \\
\hline 2059.3 & 2079.4 & 2101.7 & 2111.5 & 2043.8 & 2069.1 & 2094.7 & \\
\hline 2130.4 & 2151.0 & $\ldots$ & . . & 2114.9 & 2140.2 & 2165.9 & \\
\hline$\ldots \ldots$ & $\ldots \ldots$ & . . & $\therefore$ & 2184.8 & 2209.5 & $\ldots$ & \\
\hline$\ldots \ldots$ & 2294.1 & $\ldots \ldots \ldots$ & $\ldots \ldots$ & 2253.8 & $\ldots \ldots$ & $\ldots \ldots$ & \\
\hline$\ldots \ldots$ & 2364.1 & $\ldots \ldots \ldots$ & $\ldots \ldots$ & $\ldots \ldots \ldots$ & $\ldots \ldots$ & $\ldots \ldots$ & \\
\hline$\ldots$ & 2434.9 & $\ldots \ldots \ldots$ & & & & $\ldots \ldots$ & \\
\hline$\ldots \ldots$ & 2507.5 & $\ldots \ldots \ldots$ & & $\cdots$ & $\ldots \ldots$ & $\ldots \ldots$ & \\
\hline$\ldots \ldots$ & 2579.3 & $\ldots \ldots \ldots$ & $\ldots \ldots$ & $\ldots \ldots$ & $\ldots \ldots$ & $\ldots \ldots$ & \\
\hline 2629.5 & $\ldots \ldots$ & $\ldots \ldots \ldots$ & $\ldots \ldots$ & $\ldots$ & $\ldots \ldots$ & 2590.7 & \\
\hline & & & & 2677.4 & & $\ldots \ldots$ & \\
\hline
\end{tabular}

Uranyl Casium Chloride.

Fluorescence.

\begin{tabular}{|c|c|c|c|c|c|c|c|c|}
\hline \multicolumn{5}{|c|}{ Green Component. } & \multicolumn{4}{|c|}{ White Component. } \\
\hline$b$ & $c$ & $d$ & $e$ & $a$ & $b$ & $c$ & $e$ & $a$ \\
\hline$\cdots$ & $\ldots \ldots \ldots$ & 1761.2 & 1778.1 & 1789.9 & 1729.8 & 1751.3 & 1775.6 & 1793.4 \\
\hline 1807.3 & 1827.2 & 1843.3 & 1860.8 & 1873.7 & 1812.3 & 1835.2 & 1858.0 & 1875.8 \\
\hline 1891.1 & 1909.9 & 1927.5 & 1944.4 & 1956.2 & 1894.3 & 1917.9 & 1941.4 & 1958.1 \\
\hline 1973.6 & 1992.0 & 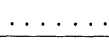 & $\ldots \ldots$ & $\ldots \ldots \ldots$ & 1978.0 & 2000.4 & $\ldots \ldots \ldots$ & $\ldots \ldots$ \\
\hline \multicolumn{9}{|c|}{ Absorption. } \\
\hline \multicolumn{5}{|c|}{ Green Component. } & \multicolumn{4}{|c|}{ White Component. } \\
\hline$\beta$ & $\gamma$ & $\delta$ & $\epsilon$ & $\alpha$ & $\beta$ & $\gamma$ & $\epsilon$ & $a$ \\
\hline 1973.9 & 1991.6 & 2007.4 & 2028.6 & 2036.4 & 1978.2 & 2002.8 & 2024.5 & 2037.1 \\
\hline 2045.6 & $\{2057.6$ & 2076.4 & 2098.6 & 2107.6 & 2049.0 & 2072.1 & 2094.9 & 2107.9 \\
\hline 2045.0 & 2065.7 & & & & & 2140.9 & 2164.9 & 2179.1 \\
\hline 2116.4 & $\{2127.9$ & 2145.2 & 2170.1 & 2179.1 & & 2212.9 & 2235.6 & $\cdots \cdots$ \\
\hline 2110.4 & 2133.1 & & & & & & & \\
\hline 2187.0 & $\left\{\begin{array}{l}2198.3 \\
2007\end{array}\right.$ & 2214.6 & $\cdots$ & $\cdots$ & & & & \\
\hline & $(2202.2$ & 2284.1 & & & & & & \\
\hline$\ldots$ & $\cdots \cdots$ & 2355.4 & & . . & & & & \\
\hline & $\ldots \ldots$ & 2426.9 & $\ldots \ldots$ & $\ldots$ & & & & \\
\hline 2467.9 & $\ldots \ldots$ & 2496.3 & $\ldots \ldots$ & $\ldots \ldots$ & & & & \\
\hline 2538.7 & $\ldots \ldots$ & 2567.4 & $\ldots \ldots$ & 2602.1 & & & & \\
\hline$\cdots \cdots$ & 2624.0 & 2637.1 & $\ldots \ldots \ldots$ & 2673.8 & & & & \\
\hline$\ldots \ldots$ & 2696.1 & $\ldots \ldots$ & $\ldots \ldots$ & $\ldots \ldots$ & & & & \\
\hline
\end{tabular}


strength of one component, accompanied by a corresponding decrease in the other component.

Table I. contains the observed positions of all the fluorescence and absorption bands measured in our determinations of the spectra of the four salts. Fig. 5 is a map of only the central portion extending as already stated, two groups into the fluorescence on the one side and two groups into the absorption, on the other.

The Effect of Low Temperature on the Resolution and Position OF THE BANDS.

In Table II. are recorded the observed positions of the fluorescence and absorption bands in the two polarized components at $-185^{\circ}$.

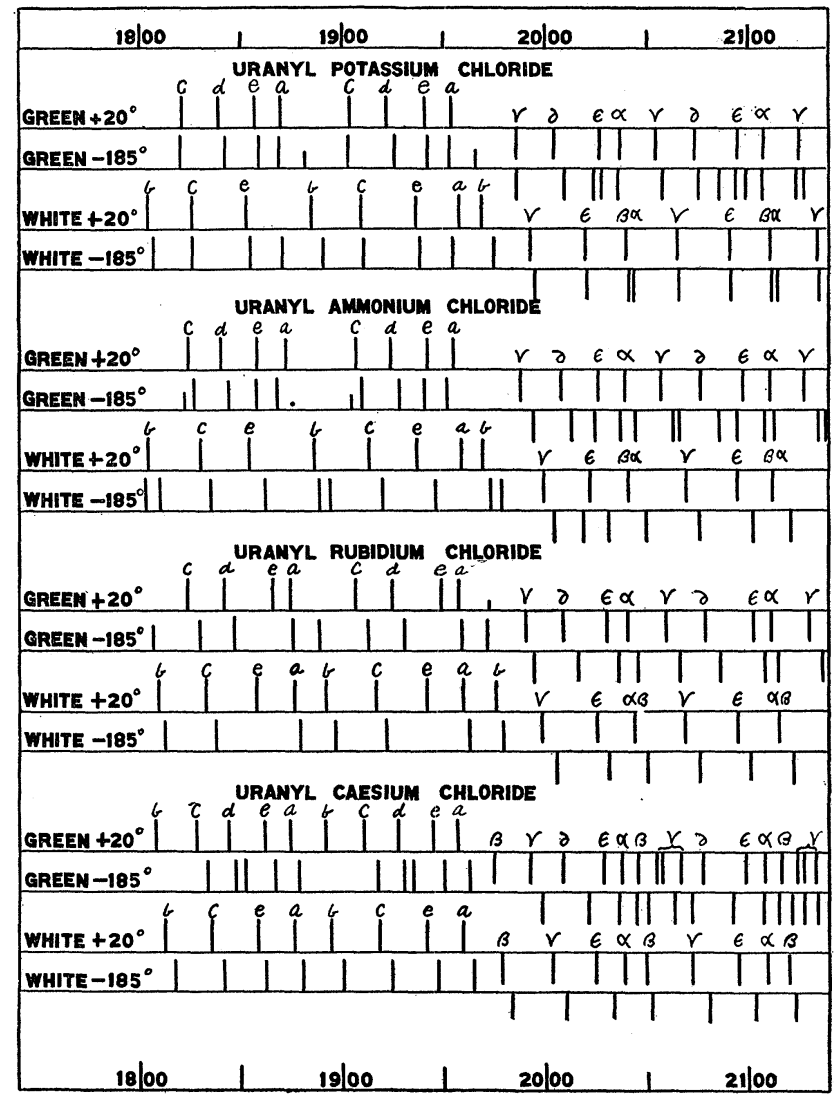

Fig. 6.

Fig. 6 is a map of the central portion of each of the spectra, corresponding to Figs. 5 and 7 . 
It has been shown in a previous paper ${ }^{1}$ that, in the case of uranyl ammonium chloride, low temperature tends to narrow all the bands, to resolve many of them and to produce shifts. These temperature shifts were then explained by assuming that the bands at $+20^{\circ}$ are close overlapping doublets the stronger components of which are weakened by lowering the temperature while the weaker components are strengthened. Such shifts occur in all of the polarized spectra here under consideration and the same explanation is applicable.

The shift is nearly always towards the violet, the only exceptions being the $a_{g}$ and $\alpha_{g}$ series and possibly the $a_{w}$ series in uranyl potassium chloride (see Fig. 6), the $e_{g}$ and $\epsilon_{g}$ series of uranyl ammonium chloride and the $a_{g}$ series of the latter salt. The change is greatest in uranyl caesium chloride and least in the potassium double chloride.

TABLE II.

Polarized Series at $-185^{\circ} \mathrm{C}$.

Uranyl Potassium Chloride.

Fluorescence.

\begin{tabular}{|c|c|c|c|c|c|c|c|c|c|}
\hline \multicolumn{6}{|c|}{ Green Component. } & \multicolumn{4}{|c|}{ White Component. } \\
\hline$c$ & $d$ & & $e$ & $a$ & $a^{\prime}$ & $b$ & $c$ & $e$ & $a$ \\
\hline 1738.4 & $\ldots \ldots$ & $\ldots$ & $\ldots$ & 1785.4 & 1797.9 & $\ldots \ldots$ & 1741.3 & 1771.9 & 1786.4 \\
\hline 1820.5 & 1842.3 & 185 & 58.1 & 1868.8 & 1881.7 & 1807.3 & 1826.2 & 1854.9 & 1870.9 \\
\hline 1903.3 & 1926.0 & 194 & 40.8 & 1953.5 & 1966.6 & 1891.4 & 1911.7 & 1938.5 & 1954.7 \\
\hline 1985.7 & & & & & $\ldots \ldots$ & 1975.5 & 1996.0 & $\cdots$ & $\ldots \ldots$ \\
\hline \multicolumn{10}{|c|}{ Absorption. } \\
\hline \multicolumn{6}{|c|}{ Green Component. } & \multicolumn{4}{|c|}{ White Component. } \\
\hline$\gamma$ & \multicolumn{2}{|l|}{$\delta^{\prime}$} & \multicolumn{2}{|r|}{$\delta$} & $\delta^{\prime \prime}$ & $\gamma$ & $\beta$ & $\epsilon$ & $a$ \\
\hline 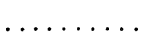 & \multicolumn{2}{|c|}{$\ldots \ldots \ldots$} & \multicolumn{2}{|c|}{2010.5} & $\ldots \ldots$ & 2000.4 & 2114.2 & 2021.0 & 2041.2 \\
\hline 2058.0 & \multicolumn{2}{|c|}{2076.6} & \multicolumn{2}{|c|}{$\ldots \ldots \ldots$} & 2086.4 & 2067.8 & 2184.8 & 2092.7 & 2112.2 \\
\hline 2128.1 & \multicolumn{2}{|c|}{2146.8} & \multicolumn{2}{|c|}{2152.9} & 2157.5 & 2137.7 & 2257.8 & 2164.0 & 2182.6 \\
\hline 2199.3 & \multicolumn{2}{|c|}{2218.7} & \multicolumn{2}{|c|}{2222.2} & 2228.8 & 2207.5 & & $\ldots \ldots$ & 2252.7 \\
\hline$\ldots \ldots \ldots$ & \multicolumn{2}{|c|}{2289.9} & \multicolumn{2}{|c|}{$\ldots \ldots \ldots$} & 2301.5 & $\ldots \ldots$ & $\ldots \ldots$ & $\ldots \ldots$ & $\ldots \ldots$ \\
\hline . & \multirow{2}{*}{\multicolumn{2}{|c|}{$\ldots \ldots \ldots$}} & \multirow{2}{*}{\multicolumn{2}{|c|}{$\cdots \cdots \cdots$}} & 2371.1 & $\ldots \ldots$ & \multirow{3}{*}{2541.9} & $\ldots \ldots$ & $\ldots \ldots$ \\
\hline & & & & & 2440.8 & & & & \\
\hline 2485.7 & & & & $\ldots \ldots$ & 2512.3 & & & & \\
\hline$\epsilon$ & \multicolumn{2}{|l|}{$\epsilon^{\prime}$} & \multicolumn{2}{|r|}{$a$} & $\gamma^{\prime}$ & & \multirow{9}{*}{6} & & \\
\hline 2024.3 & \multicolumn{2}{|c|}{2028.4} & \multicolumn{2}{|c|}{2036.2} & & & & & \\
\hline 2094.2 & \multicolumn{2}{|c|}{2099.1} & \multicolumn{2}{|c|}{2106.6} & 2124.0 & & & & \\
\hline 2164.5 & \multicolumn{2}{|c|}{2169.7} & \multicolumn{2}{|c|}{2177.8} & 2193.5 & & & & \\
\hline$\ldots \ldots \ldots$ & \multicolumn{2}{|c|}{2241.4} & & 48.5 & $\ldots \ldots$ & & & & \\
\hline$\ldots \ldots \ldots$ & $\ldots \ldots$ & $\cdots$ & $\ldots$ & $\ldots \ldots$ & $\cdots \cdots$ & & & & \\
\hline$\ldots \ldots \ldots$ & 2384 . & & & & $\cdots$ & & & & \\
\hline$\ldots \ldots \ldots$ & $\ldots \ldots$ & $\cdots$ & $\ldots$ & $\ldots \ldots$ & $\ldots \ldots$ & & & & \\
\hline$\ldots \ldots \ldots$ & .12525 . & & & 32.9 & $\ldots \ldots$ & & & & \\
\hline
\end{tabular}

${ }^{1}$ Nichols and Merritt, Phys. Rev., 2, VI., p. 358. 


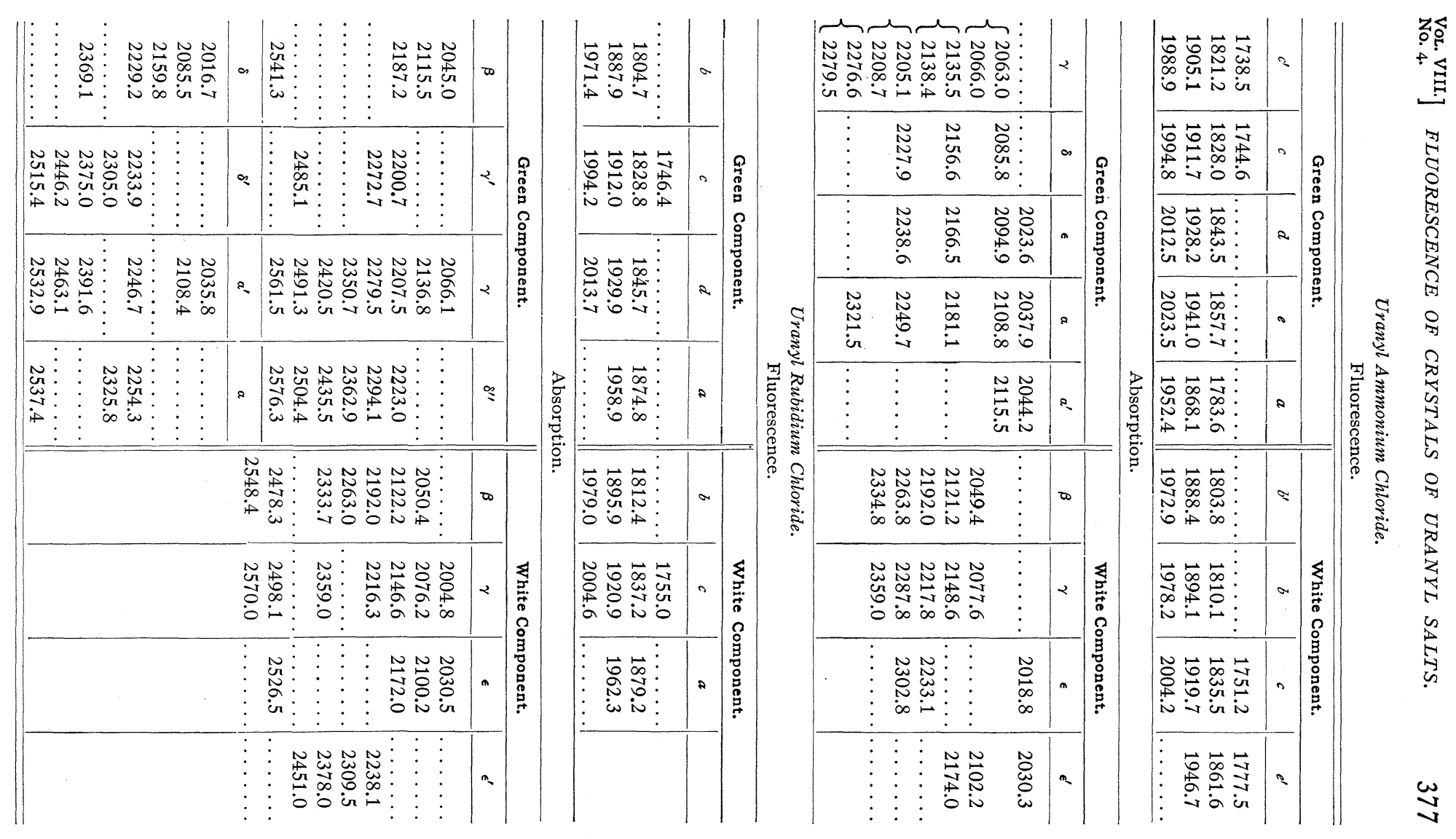


Uranyl Casium Chloride.

Fluorescence.

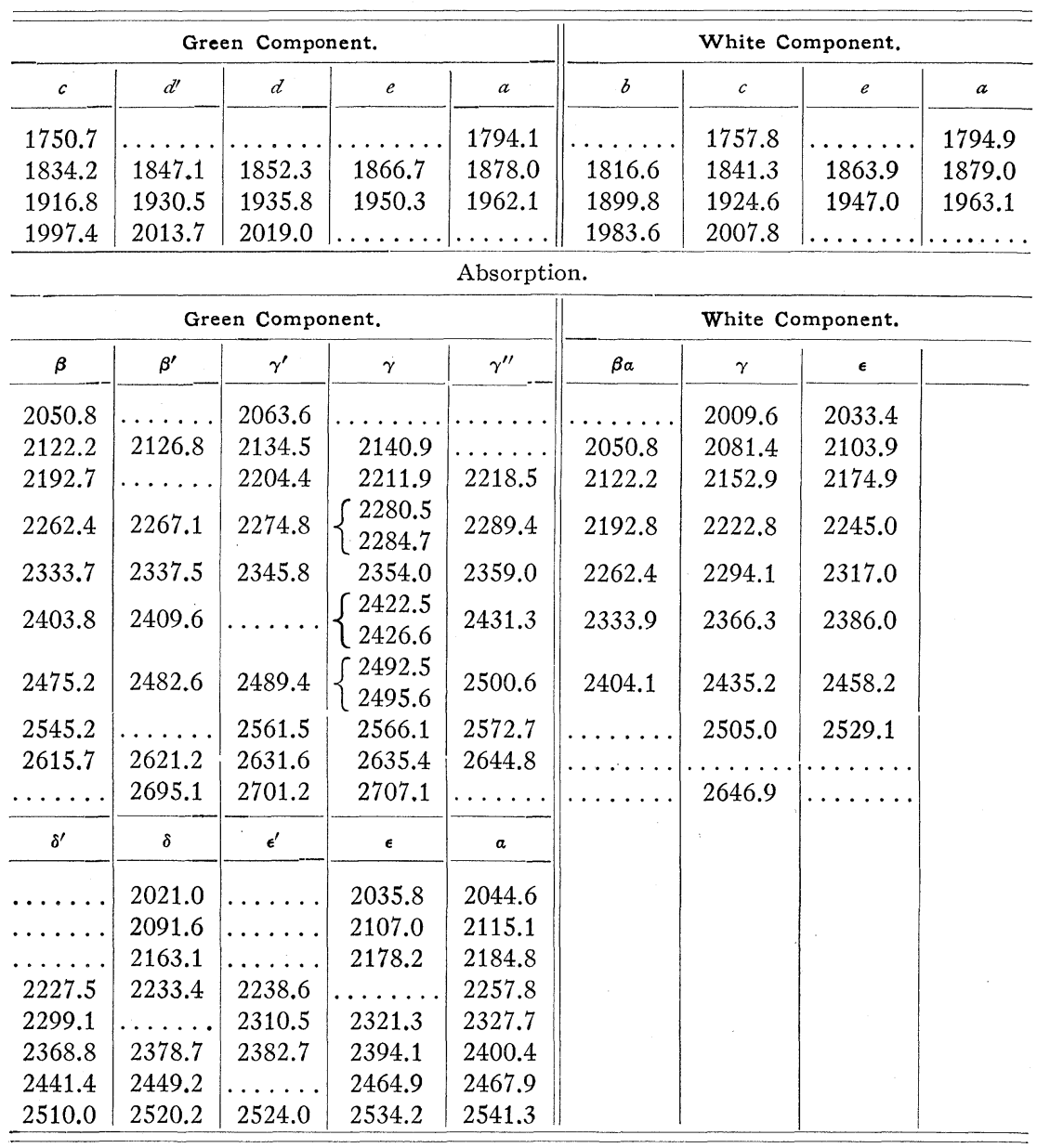

In general the fluorescence bands shift in the same direction and by the same amount as the related absorption bands but there are some puzzling exceptions to this rule to be considered in a following section.

The increased resolution of the spectra upon cooling, shows itself in the doubling of many bands which appear single at $+20^{\circ}$; an effect which is particularly noticeable in the absorption spectra. Thus the $\gamma_{g}$ series of the potassium salt tends to double at 2058.0 and becomes clearly double at 2128.I and 2199.3. The $\delta_{g}$ and $\epsilon_{g}$ series of the same salt are doubled and the $\beta \alpha$ series of $+20^{\circ}$ which was assumed from the relations of the spectrum to be an unresolved doublet is separated into a $\beta_{w}$ and an $\alpha_{w}$ series at $-185^{\circ}$. Other examples of doubling may 
be noted in the case of $c_{g}, \gamma_{g}, \alpha_{\theta}$ and $b_{w}$ of uranyl ammonium chloride, $\alpha_{g}, \alpha_{w}$ and $\beta_{w}$ of the rubidium salt and $\beta_{w}, d_{g}$ and $\partial_{g}$ of the cæsium salt.

On the Frequency Intervals of Fluorescence and Absorption.

During the preliminary study of the fluorescence and absorption of uranyl ammonium chloride the symmetry of the spectrum was such as to lead to the suspicion that the various homologous series would be found to have the same constant frequency interval. The final tabulation of results, ${ }^{1}$ however, after many redeterminations of what seemed to be discordant values, showed that while the departures from uniformity were in general scarcely larger than the errors of observation they were to some extent systematic and indicated slightly different values for the various series. The $c$ bands in particular which were a composite of what in these later studies we have designated as $c_{g}$ and $c_{w}$ of the polarized spectrum were found to have an unquestionably smaller interval than the other series of the group.

It will be seen from Table III. that this is true for both $c_{g}$ and $c_{w}$ in the case of all four salts at $+20^{\circ}$ and that with the possible exception of $a_{w}$ which is an exceedingly feeble component, visible only in two of the salts and very difficult of determination, all other series are very nearly of the same interval not only in the same salt but in all the salts. When however we make further averages of the average intervals from Table

TABLE III.

Average Frequency Intervals. $+20^{\circ} \mathrm{C}$.

Fluorescence Series.

\begin{tabular}{|c|c|c|c|c|c|c|c|c|c|}
\hline \multicolumn{5}{|c|}{ Green Component. } & \multicolumn{5}{|c|}{ White Component. } \\
\hline Series. & $\mathbf{K}$ & $\mathrm{NH}_{4}$ & $\mathrm{Rb}$ & $\mathrm{Cs}$ & Series. & $\mathbf{K}$ & $\mathrm{NH}_{4}$ & $\mathrm{Rb}$ & $\mathrm{Cs}$ \\
\hline$b_{g}$. & $\ldots \ldots$ & $\ldots \ldots$ & $\ldots \ldots$ & 82.9 & $b_{w} \ldots$ & 83.0 & 83.4 & 83.6 & 82.9 \\
\hline$c_{g} \ldots \ldots$ & 81.9 & 82.8 & 82.2 & 82.6 & $c_{w} \ldots \ldots$ & 82.1 & 82.9 & 83.3 & 82.8 \\
\hline$d_{g} \ldots \ldots$ & 83.0 & 83.5 & 83.1 & 83.3 & & $\ldots \ldots$ & $\ldots \ldots$ & $\ldots \ldots$ & $\ldots$ \\
\hline$e_{g} \ldots \ldots$ & 83.2 & 83.3 & 83.5 & 83.3 & $e_{w} \ldots \ldots$ & 83.5 & 83.1 & 83.5 & 83.1 \\
\hline$a_{g} \ldots \ldots$ & 83.4 & 83.8 & 83.2 & 82.9 & $a_{w} \ldots$ & 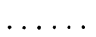 & $\ldots \ldots$ & 82.9 & 82.4 \\
\hline
\end{tabular}

Absorption Series.

\begin{tabular}{c|c|c|c|c||c|c|c|c|c}
\hline & $\mathbf{K}$ & $\mathrm{NH}_{4}$ & $\mathrm{Rb}$ & $\mathrm{Cs}$ & & $\mathbf{K}$ & $\mathrm{NH}_{4}$ & $\mathrm{Rb}$ & $\mathrm{Cs}$ \\
\hline$\beta_{g} \ldots \ldots$ & $\ldots \ldots$ & $\ldots \ldots$ & $\ldots \ldots$ & 70.5 & $\beta_{w} \ldots \ldots$ & 71.5 & 71.3 & 70.4 & 70.8 \\
$\gamma_{g} \ldots \ldots$ & 71.3 & 70.7 & 71.2 & 70.6 & $\gamma_{w} \ldots \ldots$ & 71.3 & 70.3 & 70.0 & 70.5 \\
$\delta_{g} \ldots \ldots$ & 71.1 & 70.5 & 70.2 & 70.5 & $\ldots \ldots$ & $\ldots \ldots$ & $\ldots \ldots$ & $\ldots \ldots$ & $\ldots \ldots$ \\
$\epsilon_{g} \ldots \ldots$ & 70.8 & 70.8 & 71.7 & 71.0 & $\epsilon_{w} \ldots \ldots$ & 70.4 & 71.7 & 70.8 & 70.4 \\
$\alpha_{g} \ldots \ldots$ & 70.7 & 71.5 & 71.1 & 70.8 & $\alpha_{w} \ldots \ldots$ & 71.5 & 71.3 & 70.4 & 71.4 \\
\hline
\end{tabular}

1 Nichols and Merritt, Phys. Rev., 2, VI, p. 358. 
Average Frequency Intervals. $-185^{\circ} \mathrm{C}$.

Fluorescence Series.

\begin{tabular}{|c|c|c|c|c|c|c|c|c|c|}
\hline \multicolumn{5}{|c|}{ Green Component. } & \multicolumn{5}{|c|}{ White Component. } \\
\hline Series. & $\mathbf{K}$ & $\mathbf{N H}_{4}$ & $\mathrm{Rb}$ & Cs & Series. & $\mathbf{K}$ & $\mathrm{NH}_{4}$ & $\mathbf{R b}$ & Cs. \\
\hline$b_{g}$. & 84.0 & $\ldots \ldots$ & 83.4 & & $b_{w} \ldots \ldots$ & 84.1 & 84.1 & 83.2 & 83.6 \\
\hline$c_{g} \ldots \ldots$ & 82.5 & 83.4 & 82.6 & 82.2 & $c_{w} \ldots \ldots$ & 84.8 & 84.4 & 83.9 & 83.3 \\
\hline$d_{g} \ldots \ldots$ & 83.7 & 84.4 & 83.9 & 83.3 & & $\ldots \ldots$ & 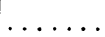 & . & $\ldots \ldots$ \\
\hline$e_{g} .$. & 83.3 & 83.2 & $\ldots \ldots$ & 83.6 & $e_{w} \ldots \ldots$ & 83.0 & . & $\ldots \ldots$ & 83.1 \\
\hline$a_{g} \ldots \ldots$ & 84.1 & 84.4 & 84.1 & 84.1 & $a_{w} \ldots$ & 84.0 & & 83.1 & 84.1 \\
\hline
\end{tabular}

Absorption Series.

\begin{tabular}{c|c|c|c|c||c|c|c|c|c}
\hline & $\mathbf{K}$ & $\mathbf{N H}_{4}$ & $\mathbf{R b}$ & $\mathbf{C s}$ & & $\mathbf{K}$ & $\mathbf{N H}_{4}$ & $\mathbf{R b}$ & $\mathbf{C s}$ \\
\hline$\beta_{g} \ldots \ldots$ & $\ldots \ldots$ & $\ldots \ldots$ & 70.9 & 70.5 & $\beta_{w} \ldots \ldots$ & 71.3 & 71.3 & 70.8 & 70.6 \\
$\gamma_{g} \ldots$ & 71.5 & 70.9 & 70.7 & 70.8 & $\gamma_{w} \ldots \ldots$ & 69.8 & 70.6 & 70.3 & 70.7 \\
$\boldsymbol{\delta}_{g} \ldots \ldots$ & 70.3 & 71.1 & 71.3 & 71.4 & $\ldots \ldots \ldots$ & $\ldots \ldots$ & $\ldots \ldots$ & $\ldots \ldots \ldots$ & $\ldots \ldots$ \\
$\boldsymbol{\epsilon}_{g} \ldots \ldots$ & 71.8 & 71.5 & $\ldots \ldots$ & 71.0 & $\boldsymbol{\epsilon}_{w} \ldots \ldots$ & 71.4 & 70.7 & 71.1 & 70.9 \\
$\alpha_{g} \ldots \ldots$ & 71.0 & 70.9 & 70.6 & 71.1 & $\alpha_{w} \ldots \ldots$ & 70.4 & $\ldots \ldots$ & $\ldots \ldots$ & 70.6 \\
\hline
\end{tabular}

III., taking the mean of all green components of fluorescence, then of all white components, for each salt separately; and do the same for the absorption intervals we find an approach to systematic arrangement which is suggestive if not altogether conclusive. (See Table IV).

TABLE IV.

General Averages of Intervals (By Salts).

Fluorescence.

\begin{tabular}{l|c|c|c|c}
\hline & $\mathbf{N H}_{4}$ & $\mathbf{K}$ & $\mathbf{R b}$ & $\mathbf{C s}$ \\
\hline Green $+20^{\circ}$ and $-185^{\circ} \ldots \ldots \ldots$ & 83.60 & 83.25 & 83.25 & 83.19 \\
White $+20^{\circ}$ and $-185^{\circ} \ldots \ldots \ldots$ & 83.78 & 83.43 & 83.42 & 83.16 \\
\hline All Fluorescence $\ldots \ldots \ldots \ldots$ & 83.69 & 83.34 & 83.33 & 83.17 \\
\hline & Absorption. & & \\
\hline Green $+20^{\circ}$ and $-185^{\circ} \ldots \ldots \ldots$ & 70.99 & 71.07 & 70.96 & 70.74 \\
White $+20^{\circ}$ and $-185^{\circ} \ldots \ldots \ldots$ & 71.02 & 70.96 & 70.55 & 70.70 \\
\hline All Absorption $\ldots \ldots \ldots$ & 71.00 & 71.01 & 70.75 & 70.72 \\
\hline \hline
\end{tabular}

Both components of the fluorescence spectrum show an average interval in the inverse order of the molecular weights and while the absorption series do not give so decisive an indication the salts of lesser molecular weight $\mathrm{NH}_{4}$ and $\mathrm{K}$ show again a longer interval than do $\mathrm{Rb}$ and Cs. Averaging by series affords no such direct indication as to differences of interval; as will appear from Table V. 
Vol. VIII.] FLUORESCENCE OF CRYSTALS OF URANYL SALTS.
No. 4.

TABLE V.

General Averages of Intervals (By Series).

Fluorescence.

\begin{tabular}{|c|c|c|c|c|c|c|c|}
\hline & Series. & Green. & & & Series. & White. & \\
\hline & $+20^{\circ}$ & $-185^{\circ}$ & Av. & & $+20^{\circ}$ & $-185^{\circ}$ & Av. \\
\hline$e_{g}$. & 83.33 & 83.37 & 83.35 & & 83.37 & 83.05 & 83.17 \\
\hline$b_{g} .$. & $\ldots$ & 83.70 & 83.70 & $b_{w}$ & 83.23 & 83.75 & 83.49 \\
\hline$a_{g} \ldots$ & 83.26 & 84.18 & 83.72 & $a_{w}$. & 82.80 & 83.73 & 83.74 \\
\hline$d_{g} .$. & 83.23 & 83.83 & 83.53 & $d_{w}$. & & & \\
\hline$c_{g} \ldots \ldots$ & 82.38 & 82.68 & 82.53 & $c_{w} \ldots \ldots$ & 82.78 & 84.10 & 83.44 \\
\hline Av...... & 83.05 & 83.54 & 83.37 & Av...... & 83.05 & 83.66 & 83.36 \\
\hline \multicolumn{8}{|c|}{ Absorption. } \\
\hline & $+20^{\circ}$ & $-185^{\circ}$ & $\mathrm{Av}$ & & $+20^{\circ}$ & $-185^{\circ}$ & Av. \\
\hline $\boldsymbol{\epsilon}_{g} \ldots$ & 71.07 & 71.40 & 71.23 & $\epsilon_{w}$ & 70.82 & 71.02 & 70.90 \\
\hline$\beta_{g} \ldots \ldots$ & $\ldots \ldots$ & $\ldots \ldots$ & $\ldots \ldots$ & $\beta_{w} \ldots \ldots$ & 71.00 & 71.00 & 71.00 \\
\hline$\alpha_{g} \ldots \ldots$ & 71.02 & 70.90 & 70.96 & $\alpha_{w} \ldots \ldots$ & 70.90 & 70.70 & 70.80 \\
\hline$\partial_{g} \ldots \ldots$ & 70.58 & 71.02 & 70.75 & $\partial_{w} \ldots \ldots$ & $\ldots \ldots$ & $\ldots \ldots$ & $\ldots \ldots$ \\
\hline$\gamma_{g} \ldots \ldots$ & 70.95 & 70.98 & 70.96 & $\gamma_{w} \ldots \ldots$ & 70.50 & 70.35 & 70.42 \\
\hline Av....... & 70.90 & 71.07 & 70.97 & $\mathrm{Av} \ldots \ldots$ & 70.81 & 70.77 & 70.78 \\
\hline
\end{tabular}

It will be noted that while the averages for the green and white components of fluorescence are in very close agreement at $+20^{\circ}$ and also at $-185^{\circ}$ there is a difference of about 0.5 between the averages for $+20^{\circ}$ and those for $-185^{\circ}$ also that the interval is greater for each individual series at $-185^{\circ}$ than at $+20^{\circ}$ with the single exception of $\epsilon_{w}$. This difference does not appear however in the case of the absorption intervals.

On the other hand differences so large are not to be regarded as errors of observation it being possible to determine the average interval of any series, excepting possibly $a_{g}$ and $a_{w}$ which are very weak and rather vague, within about 0.2. It does not follow however that the bands are really thus irregularly placed. The discrepancies are due rather to the fact that resolution is not equally complete in all portions of the spectrum and that on cooling the crystal structure was more or less disturbed and the polarization always much less complete. The anomalous values, above 84 frequently observed at $-\mathrm{I} 85^{\circ}$ (see Table III.) are probably due to varying components of the opposite polarization superimposed on the bands in question and producing a false shift. Thus for example the position of $c_{w}$ would be modified by the presence of the overlapping of $d_{g}$ or $c_{g} ; d_{g}$ by $c_{g}$, etc. In short it is probable that if observations could be had on crystals which at $-\mathrm{I} 85^{\circ}$ preserved their structure the difference in interval between $+20^{\circ}$ and $-185^{\circ}$ would disappear. 
The Influence of Molecular Weight upon the Position of Bands.

While some doubt may be felt as to the validity of the suggestion, based upon the averages presented in the foregoing paragraphs, that

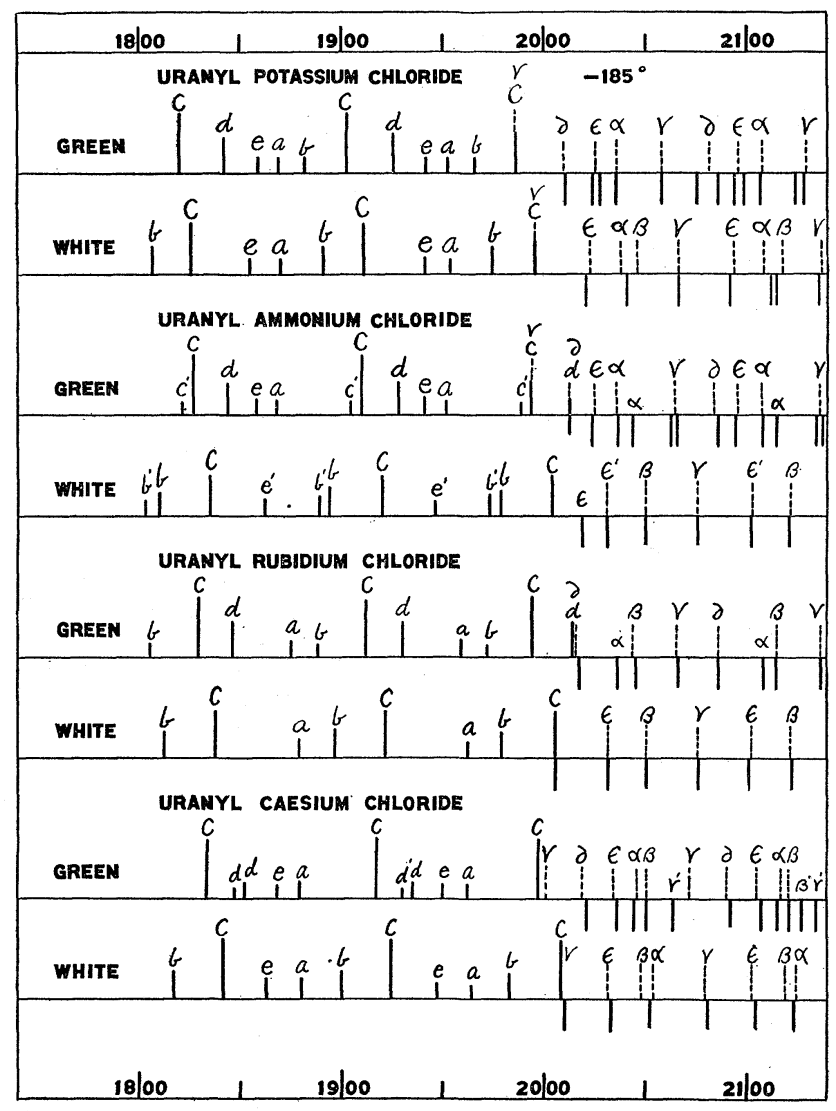

Fig. 7.

there is a relation between frequency intervals and the molecular weight, there can be no question as regards its influence upon the position of the bands.

If we select a typical region in the spectrum and arrange the bands belonging to a single group as in Table VI. we find a general drift of the various bands towards the violet as we pass from salt to salt in the order, $\mathrm{K}, \mathrm{NH}_{4}, \mathrm{Rb}, \mathrm{Cs}$.

The same drift occurs quite systematically throughout the entire fluorescence and absorption spectrum as may be seen from Fig. 8. In this chart such of the fluorescence and absorption series as are 
Vor. VIII.] FLUORESCENCE OF CRYSTALS OF URANYL SALTS.
No.4.

TABLE VI.

Green Polarization.-I $85^{\circ}$.

\begin{tabular}{|c|c|c|c|c|}
\hline & $c_{g}$ & $d_{g}$ & $e_{g}$ & $a_{g}$ \\
\hline $\begin{array}{l}\mathrm{K} \ldots \ldots \ldots \ldots \\
\mathrm{NH}_{4} \ldots \ldots \ldots \ldots \\
\mathrm{Rb} \ldots \ldots \ldots \ldots \\
\mathrm{Cs} . \ldots \ldots \ldots \ldots\end{array}$ & $\begin{array}{l}1903.3 \\
1911.7 \\
1912.0 \\
1916.8 \\
\end{array}$ & $\begin{array}{l}1842.3 \\
1843.5 \\
1845.7 \\
1852.3 \\
\end{array}$ & $\begin{array}{l}1940.8 \\
1941.0 \\
\ldots \ldots \\
1950.3\end{array}$ & $\begin{array}{l}1868.8 \\
1868.1^{1} \\
1874.8 \\
1878.5 \\
\end{array}$ \\
\hline \multicolumn{5}{|c|}{ White Polarization. $-\mathrm{I} 85^{\circ}$. } \\
\hline & $b_{w}$ & $c_{w}$ & $e_{w}$ & $a_{w}$ \\
\hline $\begin{array}{l}\mathrm{K} \ldots \ldots \ldots \ldots \\
\mathrm{NH}_{4} \ldots \ldots \ldots \ldots \\
\mathrm{Rb} \ldots \ldots \ldots \ldots \\
\mathrm{Cs} \ldots \ldots \ldots \ldots\end{array}$ & $\begin{array}{l}1891.4 \\
1894.1 \\
1895.9 \\
1899.8\end{array}$ & $\begin{array}{l}1911.7 \\
1919.7 \\
1920.9 \\
1924.6\end{array}$ & $\begin{array}{l}1854.9 \\
\ldots \ldots \\
\ldots \ldots \\
1862.5\end{array}$ & $\begin{array}{l}1870.9 \\
\ldots \ldots \\
1879.2 \\
1879.9\end{array}$ \\
\hline
\end{tabular}

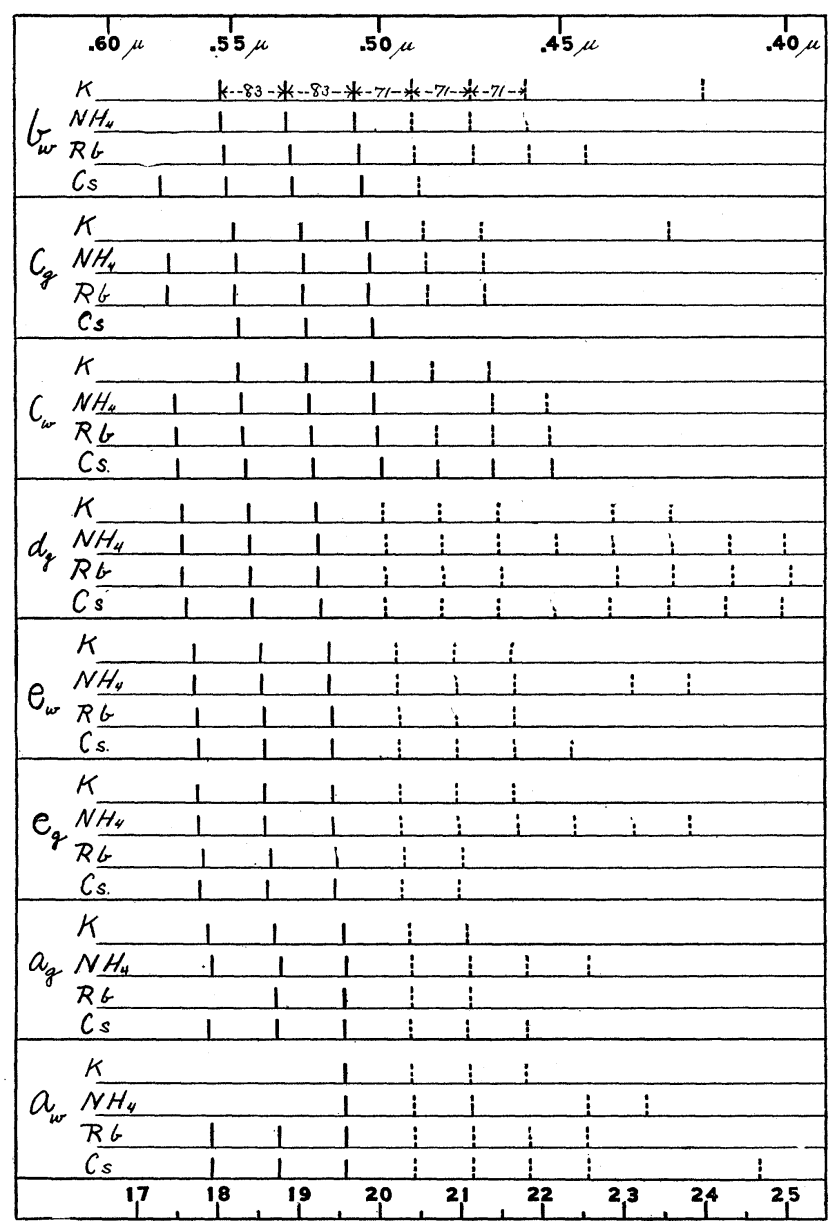

${ }^{1}$ Within experimental error.

Fig. 8. 
present in all four salts at $+20^{\circ}$ are plotted on the frequency scale. The solid lines represent observed fluorescence bands; the dotted lines represent observed absorption bands; no hypothetical values are indicated. The order of the salts is the same as in Table VI. and follows that given by A. E. Tutton in his Treatise on Crystalline Structure and Chemical Constitution (London, 1916). He found for both single and double salts of the alkali metals that several of their optical properties such as refractive index, etc., follow the order of the molecular weights but that in the ammonium salts the $\mathrm{NH}_{4}$ radical often acts as if it were much heavier than the combined weights of its components would indicate so that its position is quite close to rubidium and sometimes on the side towards cæsium. It will be observed that there are several examples of this in Fig. 8; particularly in the case of the $c_{g}$ series.

\section{SUMmARY.}

I. A previous study of the polarized spectrum of uranyl ammonium chloride has been extended to include uranyl potassium chloride, uranyl rubidium chloride and uranyl cæsium chloride.

2. These four salts crystallize in the triclinic system. The crystals are pleochroic and their fluorescence spectra and absorption spectra are polarized.

3. The spectra differ from those of other uranyl compounds, thus far examined, in that both in the fluorescence and absorption regions each band is resolved at $+20^{\circ} \mathrm{C}$. into a group of five bands forming homologous series of constant frequency-interval.

4. The structure of the fluorescence spectrum is essentially the same in the different salts; the spacing of the bands of each group repeating itself in the successive groups excepting in the reversing region the appearance of which is modified by the overlapping of fluorescence and absorption.

5. Each of the five bands, which constitute a group is a doublet the two components of which are polarized at right angles to one another.

6. The frequency interval is the same or nearly the same for each series in a given salt.

7. Variations in the average interval for the four salts are scarcely greater than the errors of observation but there are indications of a very slight decrease of interval with increase of molecular weight and this applies alike to fluorescence and absorption series.

8. The position, in the spectrum, of a given band varies slightly but systematically with the molecular weight of the salt. The order of diminishing wave-lengths is $\mathrm{K} ; \mathrm{NH}_{4} ; \mathrm{Rb}$; $\mathrm{Cs}$; the shift from $\mathrm{K}$ to $\mathrm{Cs}$ 
VoL. VIII.] FLUORESCENCE OF CRYSTALS OF URANYL SALTS.
No. 4.

being of the order of five Angström units. This shift is in the same direction-from red towards violet-for all the homologous series and of the same size within the errors of observation.

9. Cooling to the temperature of liquid air produces the usual narrowing of bands, apparent shifts of position and apparent changes of interval; all of which changes are explained by the relative enhancement or diminution of components of the bands.

Physical Laboratory of Cornell University, June, I9I6. 